\title{
Alcohol Drinking Habits and Its Leading Factors of Undergraduate Students: Using Cross-Sectional Study Design
}

\author{
Solomon Abebaw Andargie*, Assaye Belay Gelaw \\ Department of Statistics, Mizan-Tepi University, Tepi, Ethiopia \\ Email address: \\ solabew@gmail.com (S. A. Andargie), abstat23@gmail.com (A. B. Gelaw) \\ ${ }^{*}$ Corresponding author
}

\section{To cite this article:}

Solomon Abebaw Andargie, Assaye Belay Gelaw. Alcohol Drinking Habits and Its Leading Factors of Undergraduate Students: Using CrossSectional Study Design. American Journal of Life Sciences. Vol. 9, No. 5, 2021, pp. 120-126. doi: 10.11648/j.ajls.20210905.13

Received: July 26, 2021; Accepted: August 5, 2021; Published: September 26, 2021

\begin{abstract}
Alcohol-related leading factors are prevalent, and the important public health problem. Alcohol has represented the issue of the global burden of disease. Alcohol consumption requires a consideration of the amount of alcohol consumed and drinking habits. Thus, the primary objective of this study was to determine the leading factor of the alcohol drinking habits of undergraduate students at Mizan-Tepi University, Ethiopia. The sample of 77 students were interviewed and selected by using a stratified random sampling technique. The data were collected by using self-structured questionnaires. The Binary logistic regression model was correctly fitted the data and the Hosmer-Lemeshow test was used to test the goodness of fit of the model. SPSS statistical software (version 20) was used to analyze the data and a cross-tab table was used to summarize the descriptive statistics and chi-square test of independence. Out of 77 sampled students, forty-two $(54.55 \%)$ of students have alcohol drinking habit and thirty-five (45.45\%) of students have not alcohol drinking habit. The chi-square test showed that gender of an individual ( $p$-value $=0.039<0.05)$, departments $(p$-value $=0.009<0.05)$ and initiation $(p-v a l u e=0.009<0.05)$ were significantly associated with alcohol drinking habit of students in Mizan-Tepi University, in case of Tepi Campus, Ethiopia at $5 \%$ level of significance. The odds ratio of the mathematics department is 0.0076 times less likely to have alcohol-drinking habits as compared to biology department when all other variables are remaining constant and the study concluded that alcohol-drinking habit of students is high.
\end{abstract}

Keywords: Alcohol Drinking Habit, Logistic Regression, Odds Ratio

\section{Introduction}

The university years do not only involve personal growth and intellectual development. They are also a period in which many students consume large quantities of alcohol and experience several associated adverse effects [1]. Alcohol use and associated alcohol-related harm (ARH) are among the most prevalent and important public health problems plaguing this generation [2]. Alcohol is a chemical substance that affects the process of mind or body. People begin taking alcohol for various reasons such as to feel good to better and to find out what it is like and to fit the consumption of a small amount of alcohol leads to a sense of wellbeing and relaxation [3].

Available research indicates that approximately $80 \%$ of college students drink and that half of college student drinkers engage in heavy episodic drinking. Furthermore, the institutions they attend expend valuable resources to deal with institutional and personal consequences of their behavior [4]. College presidents and research scientists were put together to ensure that the product will at the same time contribute to the scientific basis for addressing college drinking and will be relevant to the practical challenges faced by college administrators. The Task Force was charged with integrating available scientific research with experiences reported by administrators, service providers and students [5].

Both alcohol consumption and consumed alcoholic beverage types and socio-demographic relationships are aimed to be revealed. Significant differences were found in socio-demographic relationships with alcohol consumption 
and alcoholic beverages in India [6]. The study aimed to determine the factors associated with parents' belief in the appropriateness of giving alcohol to minors. The parents of Western Australia study surveyed their alcohol use habits and their behaviors, beliefs and attitudes, and their children's alcohol consumption and demographic characteristics [7].

Drinking on college campuses may seem to be entrenched and impervious to intervention; however, it is potentially modifiable with carefully targeted approaches endorsed by all stakeholders including students [8]. A rate of alcohol use among college/university students is growing, for example, alcohol use among students of the university Sao Paulo Brazil between 1996 and 2001 showed an increase from $88.6 \%$ to $92 \%$ it also continues to be the most prevalent problem among college student in the United States [9]. About $40.5 \%$ did something that caused them to regret while someone they know criticized 32.3\% local surveys among university students in South Africa showed the presence of higher level of risky drinking than in the national survey. In the year 1998, the pattern of use of alcohol chat and cigarette among 479 medical and Para was studied [10]. Another study was conducted in 2007 for era districted North West Ethiopia indicates $70.67 \%$ alcohol use and $50.6 \%$ chat chewing most students to this substance manly for a family relative reason and peer perjure. Another study was conducted fawn indicated that students with digressive symptoms where more like to report alcohol consumption [11].

Alcohol causes the deterioration of the central nervures system with actual brain shrinkage in the male the part of the central nervure system controlling libido may be permanently destroyed. Many alcohols have limited food intake and suffer frame vitamin B group deficiency in pregnancy heavy drinking can result in cottontail damage to the feats known as fetal alcohol syndrome [12]. Alcohol is artificially recognized to be a teratogen, besides economic impacts. The cumulative effect of alcohol consumption has the potential to influence human behavior alcohol lowers self-esteem. This can result in destructive worthless feelings. Individual that drink is at risk of conflicts with family, friends, and co-work. Alcoholic drinking is expensive and can run away a large part of the family budget. Gambling and problem Grambling were also significantly associated with Bing drinking Alcohol abuse and heavy or problem drinking [13].

\section{Methods}

The study was conducted at Mizan-Tepi University, Tepi Campus. It is located $612 \mathrm{~km}$ southwest of National capital, Addis Ababa and about 852 kilometers from the regional capital Hawassa. Mizan-Tepi University (MTU), Tepi campus was established or started teaching-learning activities in the 2007 Gregorian calendar as a University in Ethiopia. The establishment of the University is alone with government policy and expanding quality higher education and ensuring its equitable distribution across the country.

Study Design: Cross-sectional study design was carried out. The target population for this study would be conducted on all undergraduate Natural and Computational Sciences students, 2019 in the Gregorian calendar in Mizan Tepi University, Tepi Campus, Ethiopia. Stratified Random Sampling was used. The sample size is calculated with the help of the formula [14].

$$
n=\frac{n_{o}}{1+{ }^{n_{o} / N}}, \text { Where } n_{o}=\left(Z_{\alpha / 2}\right)^{2} \frac{p q}{d^{2}}
$$

$Z_{\alpha / 2}=Z_{0.025}=1.96$ at $\alpha=0.05$, where

$\alpha$ is level of significance

$d=$ Marginal error $=0.1$

$P=0.5$ is taken (maximum variation among students on alcohol drnking habit).

$Q=$ Proportion of failure, $1-P=0.5$

$n_{o}=(1.96)^{2} \frac{0.5 * 0.5}{(0.1)^{2}}=96$, and then $\frac{n_{0}}{N}=\frac{96}{400}=0.24>0.05$.

So it needs adjustment , $n=\frac{n_{o}}{1+\frac{n_{o}}{N}}, n=\frac{96}{1+96 / 400}=77$ and the Proportion sample allocation: $n_{i}=n * N_{i} / N, i=$ $1,2,3,4,5,6,7$.

Table 1. Proportion of Sample Allocation.

\begin{tabular}{llll}
\hline Sample Stratum & Department & Population stratum & $\boldsymbol{n}_{\boldsymbol{i}}=\frac{\boldsymbol{n} * N_{\boldsymbol{i}}}{\boldsymbol{N}}$ \\
\hline$n_{1}$ & Biology & $N_{1}=74$ & 13 \\
$n_{2}$ & Chemistry & $N_{2}=78$ & 15 \\
$n_{3}$ & Mathematics & $N_{3}=26$ & 6 \\
$n_{4}$ & Physics & $N_{4}=28$ & 6 \\
$n_{5}$ & Sport science & $N_{5}=41$ & 8 \\
$n_{6}$ & Statistics & $N_{6}=69$ & 13 \\
$n_{7}$ & Geology & $N_{7}=84$ & 16 \\
\hline
\end{tabular}

Table 1: Showed that the proportional sample allocation for each department since the number of students for each department is different. Administered questionnaires with the interview were used to collect the data.

Dependent variable: status Alcohol Drinking habit: $Y=\left\{\begin{array}{c}1, \text { took any alcoho } \\ o, \text { othere wise }\end{array}\right.$

Independent variables: Age, sex of student, religion of student, previous resident, and type of drink alcohol, father education, mother education, initiation, average monthly income, and Departments.

\subsection{Chi-Square Test of Independence}

A chi-square test is used to test the association between independent variables and alcohol drinking habits of students.

$$
\text { Test statistics } \chi^{2}=\frac{\sum\left(o_{i j}-E_{i j}\right)^{2}}{E_{i j}}
$$

$\chi^{2}$ Critical value: $\chi_{\alpha}^{2}(c-1)(r-1), O_{i j}$ is observed frequency, is expected frequency, is number of columns and is number of rows [15].

\subsection{Binary Logistic Regression Model}

It is a procedure for finding the mathematical function that is best describes the relationship between the dependent and one or more independent variables. Model formulation: 


$$
\begin{gathered}
\ln \left(\frac{P_{i}}{1-P_{i}}\right)=\beta_{0}+\beta_{1} X_{1 i}+\beta_{2} X_{2 i}+\ldots \ldots . . \beta_{k} X_{k i} \\
P_{i} / 1-P_{i}=\exp \left(\beta_{0}+\beta_{1} X_{1 i}+\beta_{2} X_{2 i}+\ldots \ldots \ldots \beta_{k} X_{k i}\right)
\end{gathered}
$$

where: $P_{i}$ is the probability of success, $1-P_{i}$ is The Probability of failure, $\beta_{0}$ is constant term, $\beta$ regression coefficients and $X_{i}$ are independent variables.

\subsection{Parameter Estimation for Logistic Regression}

To estimate the parameters of logistic regression model, maximum likelihood estimation methods are mostly used. In this study, the maximum likelihood estimation technique would be applied to estimate the parameters of the model. Consider the logistic regression function.

$$
P\left(x_{i}\right)=\frac{e^{X_{i}^{\prime} \beta}}{1+e^{X_{i}^{\prime} \beta}}
$$

since observe values of $\mathrm{Y}$ say, $\mathrm{Y}_{\mathrm{i}}$ 's $(\mathrm{i}=1,2 \ldots \mathrm{n})$ are independently distributed as Bernoulli, the maximum likelihood function of $\mathrm{Y}$ is given by:

$$
L(\beta / y)=\prod_{i=1}^{n} P\left(y_{i} \mid X_{i}^{\prime}\right)=\prod_{i=1}^{n}\left[\frac{e^{X_{i}^{\prime} \beta}}{1+e^{X_{i}^{\prime} \beta}}\right]^{y_{i}}\left[\frac{1}{1+e^{X_{i}^{\prime} \beta}}\right]^{\left(1-y_{i}\right)}
$$

The objective of ML estimation is to get an estimator $\hat{\beta}=\left(\hat{\beta}_{0}, \hat{\beta}_{1}, \hat{\beta}_{2}, \ldots, \hat{\beta}_{k}\right)$ of $\beta$ which maximizes the likelihood function expressed in equation (4). Since the likelihood equation is non- linear in the parameters [1].

\section{Results}

The data were presented in Table 2 below showed that, among seventy-seven sampled students, forty-two (54.5\%) of the students have alcohol drinking habits and thirty-five $(45.5 \%)$ of the students did not have alcohol drinking habit.
Table 2. Prevalence of Alcohol Drinking Habit of Students (summary of outcome variable).

\begin{tabular}{lll}
\hline Drinking habit & Number of student $(\mathbf{n}=\mathbf{7 7})$ & Percent \\
\hline Alcohol drinking habit & 42 & 54.5 \\
Did not alcohol drinking & 35 & 45.5 \\
Total & 77 & 100.00 \\
\hline
\end{tabular}

Table 2 showed the cross-tab and chi-square test of independence and interpreted some variables: Among 77 sampled students, twenty (26.0) students whose religion is orthodox. From this, eight (10.4) students have alcohol drinking habit, and twelve (15.6) students have no alcohol drinking habit; twenty (26.0) of Muslim of the students, ten (13.0) student have alcohol drinking habit and ten (13.0) student have no alcohol drinking habit; among twelve (15.6) of Protestant student, nine (11.7) have alcohol drinking habit and three (3.9) students have no alcohol drinking habit; among thirteen (16.9) of Catholic students, seven (9.1) students have alcohol drinking habit and six (7.8) students have no alcohol drinking habit; and among twelve (15.6) students whose religion are others among mentioned above, eight (10.4) students have alcohol drinking habit four (5.2) students have no alcohol drinking habit.

Among all sampled thirty-two (41.6) female students, thirty (16.9) students have alcohol drinking habit while nineteen (24.7) students have no alcohol drinking habit; among forty-five (58.4) male students, twenty-nine (37.7) student have alcohol drinking habit while sixteen (20.7) students have no alcohol drinking habit. Likewise, among seventy-seven sampled students thirty-two (41.6) of students whose previous place of residence were urban, fourteen (18.2) have alcohol drinking habit and eighteen (23.4) students have no alcohol drinking habit; among forty-five (58.4) of students who came comes from rural, twenty-eight

\begin{tabular}{|c|c|c|c|c|c|c|}
\hline \multirow{2}{*}{ Variables } & \multirow{2}{*}{ Categories } & \multicolumn{2}{|c|}{ drinking habit of alcohol } & \multirow{2}{*}{ Total (\%) } & \multirow{2}{*}{ Chi square } & \multirow{2}{*}{$P$ value } \\
\hline & & No $(\%)$ & Yes $(\%)$ & & & \\
\hline \multirow{3}{*}{ Age } & $20-22$ & $18(23.4)$ & $23(29.8)$ & $41(53.2)$ & \multirow{3}{*}{1.915} & \multirow{3}{*}{0.384} \\
\hline & $23-25$ & $6(7.8)$ & $3(3.9)$ & $9(11.7)$ & & \\
\hline & $>25$ & $11(14.3)$ & $16(20.8)$ & $27(35.1)$ & & \\
\hline \multirow{5}{*}{ Religion } & Orthodox & $12(15.6)$ & $8(10.4)$ & $20(26.0)$ & \multirow{5}{*}{4.621} & \multirow{5}{*}{0.329} \\
\hline & Muslim & $10(13.0)$ & $10(13.0)$ & $20(26.0)$ & & \\
\hline & Protestant & $3(3.9)$ & $9(11.7)$ & $12(15.6)$ & & \\
\hline & Catholic & $6(7.8)$ & $7(9.1)$ & $13(16.9)$ & & \\
\hline & Other & $4(5.2)$ & $8(10.4)$ & $12(15.6)$ & & \\
\hline \multirow{2}{*}{ Sex } & Female & $19(24.7)$ & 13 (16.9) & $32(41.6)$ & \multirow{2}{*}{4.820} & \multirow{2}{*}{0.039} \\
\hline & Male & $16(20.7)$ & $29(37.7)$ & $45(58.4)$ & & \\
\hline \multirow{2}{*}{ Resident } & Urban & $18(23.4)$ & $14(18.2)$ & $32(41.6)$ & \multirow{2}{*}{2.574} & \multirow{2}{*}{0.109} \\
\hline & Rural & $17(22.0)$ & $28(36.4)$ & $45(58.4)$ & & \\
\hline \multirow{2}{*}{ Income } & $<500$ & $14(18.2)$ & 23 (29.9) & $37(48.1)$ & \multirow{2}{*}{1.667} & \multirow{2}{*}{0.197} \\
\hline & $500-1000$ & $21(27.2)$ & $19(24.7)$ & $40(51.9)$ & & \\
\hline \multirow{4}{*}{ Initiation } & Friends & $4(5.2)$ & $19(24.7)$ & $23(29.9)$ & \multirow{4}{*}{11.602} & \multirow{4}{*}{0.009} \\
\hline & Environment & $12(15.6)$ & $11(14.3)$ & $23(29.9)$ & & \\
\hline & Family case & $8(10.4)$ & $7(9.1)$ & $15(19.5)$ & & \\
\hline & Other & $11(14.3)$ & $5(6.5)$ & $16(20.8)$ & & \\
\hline
\end{tabular}
(36.4) students have alcohol drinking habit, and seventeen (22.0) student have no alcohol drinking habit.

Table 3. Summary of Socio-Demographic Factors and Chi-Square Test of Independence. 


\begin{tabular}{|c|c|c|c|c|c|c|}
\hline \multirow{2}{*}{ Variables } & \multirow{2}{*}{ Categories } & \multicolumn{2}{|c|}{ drinking habit of alcohol } & \multirow{2}{*}{ Total (\%) } & \multirow{2}{*}{ Chi square } & \multirow{2}{*}{ P value } \\
\hline & & No (\%) & Yes $(\%)$ & & & \\
\hline \multirow{7}{*}{ Department } & Biology & $7(9.1)$ & $6(7.8)$ & $13(16.9)$ & \multirow{7}{*}{17.021} & \multirow{7}{*}{0.009} \\
\hline & Statistics & $9(11.7)$ & $4(5.2)$ & $13(16.9)$ & & \\
\hline & math's & $3(3.9)$ & $3(3.9)$ & $6(7.8)$ & & \\
\hline & Chemistry & $9(11.7)$ & $6(7.8)$ & $15(19.5)$ & & \\
\hline & Sport & $0(0.0)$ & $8(10.4)$ & $8(10.4)$ & & \\
\hline & Physics & $4(5.2)$ & $2(2.6)$ & $6(7.8)$ & & \\
\hline & Geology & $3(3.9)$ & $13(16.9)$ & $16(20.8)$ & & \\
\hline \multirow{4}{*}{ Mother Education } & Illiteracy & $19(24.7)$ & $17(22.1)$ & $36(46.8)$ & \multirow{4}{*}{1.704} & \multirow{4}{*}{0.636} \\
\hline & Primary & $4(5.2)$ & $6(7.8)$ & $10(13.0)$ & & \\
\hline & Secondary & $10(13.0)$ & $17(22.1)$ & $27(35.1)$ & & \\
\hline & Above & $2(2.6)$ & $2(2.6)$ & $4(5,2)$ & & \\
\hline \multirow{4}{*}{ Father Education } & Illiteracy & $8(10.4)$ & $13(16.9)$ & $21(27.3)$ & \multirow{4}{*}{3.800} & \multirow{4}{*}{0.284} \\
\hline & Primary & $12(15.6)$ & $10(13.0)$ & $22(28.6)$ & & \\
\hline & Secondary & $15(19.5)$ & $16(20.8)$ & $31(40.3)$ & & \\
\hline & Above & $0(0.0)$ & $3(3.9)$ & $3(3.9)$ & & \\
\hline \multirow{5}{*}{ Types of Alcohol } & Tela & $6(7.8)$ & $11(14.3)$ & $17(22.1)$ & \multirow{5}{*}{8.188} & \multirow{5}{*}{0.085} \\
\hline & Tej & $12(15.6)$ & $20(26.0)$ & 32 (41.6) & & \\
\hline & Areke & $6(7.8)$ & $3(3.9)$ & $9(11.7)$ & & \\
\hline & Bear & $2(2.6)$ & $5(6.5)$ & $7(9.1)$ & & \\
\hline & Other & $9(11.7)$ & $3(3.9)$ & $12(15.6)$ & & \\
\hline
\end{tabular}

It is clearly seen in Table 3, sex of individual ( $\mathrm{p}$-value $<0.05)$, departments (p-value $<0.05)$ and initiation (pvalue $<0.05)$ are significantly an associated with alcohol drinking habit.

Based on Table 4, p-value (0.859) is greater than the $\alpha$ value then do not reject the Hosmer and Lemeshow from the above output indicating there is sufficient evidence for the model is fitting the data adequately.

Table 4. Hosmer and Lemeshow Test.

\begin{tabular}{lll}
\hline Chi-square & Df & Sig. \\
\hline 3.980 & 8 & 0.859 \\
\hline
\end{tabular}

Table 5. Parameter Estimates of Binary logistic Regression Model.

\begin{tabular}{llll}
\hline Variables & Estimates (Sd.error) & df & Wald test \\
\hline Departments & & 6 & 5.689 \\
Statistics & $-9.574(4.753)^{*}$ & 1 & 4.058 \\
Mathematics & $-12.880(5.931)^{*}$ & 1 & 4.717 \\
Chemistry & $-7.265(6.383)$ & 1 & 1.295 \\
Sport science & $-9.360(4.604)^{*}$ & 1 & 4.133 \\
Physics & $21.387(9862.093)$ & 1 & .000 \\
Geology & $-7.857(4.130)$ & 1 & 3.619 \\
500-1000 birr & $4.452(2.157)^{*}$ & 1 & 4.261 \\
Types of alcohol & & 4 & 6.285 \\
Teji & $6.945(3.096)^{*}$ & 1 & 5.034 \\
Areki & $8.007(3.988)^{*}$ & 1 & 4.031 \\
Bear & $8.164(5.146)$ & 1 & 2.517 \\
Others & $8.676(4.437)$ & 1 & 3.823 \\
Initiation concerns & & 3 & 7.257 \\
Environment factor & $8.319(3.233)^{*}$ & 1 & 6.621 \\
Family case & $3.774(2.424)$ & 1 & 2.423 \\
Other factors & $-3.140(2.677)$ & 1 & .376 \\
Constant & $21.605(18418.425)$ & 1 & .000 \\
\hline
\end{tabular}

The fitted model is $\log$ it $(\pi)=21.605-9.574_{\text {statistics }}-12.8_{\text {Mathematics }}-9.36_{\text {sport science }}+4.452_{500-1000 \text { birr }}+$ $6.945_{\text {Teji }}+8.007$ areki $\left.+8.319_{\text {environmental factor }}\right)$

The log odd type of alcohol is 6.945 indicates a direct positive relationship between alcohol drinking habits of students and types of alcohol. The odds ratio Teji is 1030.3 times more likely to affect alcohol drinking habit of undergraduate students as compared to Tela when all other variables remain constant.
The log odds of income is 4.452 indicates that a direct relationship between alcohol drinking habit of undergraduate students and income status. The odds ratio (OR) of income (500-1000) is 85.788 times more likely to affect the alcohol drinking habit of undergraduate students compared to those their income is $<500$ when all other variables remain 
constant. The odds ratio of initiation of alcohol drinking habit is 4101.357 times more likely to affect the alcohol drinking habit of undergraduate students as compared initiation of friends when all other variables remain constant.

\section{Discussion}

The finding revealed that the prevalence of alcohol drinking habit among students in the university is 54.5 and it is too much high as compared to the study done on high school students in Ethiopia, Dire Dawa showed that the current alcohol drinking habit is $34.5 \%$ and $19.6 \%$. And a similar study reported in the Ethiopian Demographic and Health Survey, the prevalence of alcohol drinking status is $35 \%$ [16]. It indicated that the issue needs intervention and a special controlling management system in the university or study area is mandatory.

The current study also a high prevalence of alcohol drinking as compared to the study done among secondary school students in Ambo Town and its prevalence of alcohol drinking is $35.4 \%[17]$ and it is a challenge that needs quick response due to the alarming rate of involvement young students [18]. The prevalence of alcohol abusers in secondary school students (54\%) in Kisumu Town, East Kenya is highly related to the current study [19]. Up to $35 \%$ of the alcohol abusers in Pakistan reported their parents are also abusing drugs [20], according to the US national survey; $78 \%$ of adolescents used alcohol. Out of these, $47 \%$ reported regularly drinking alcohol [21], one study conducted at large scale in Maryland, USA, reported that $28 \%$ of adolescents exposed to movies depicting alcohol use or involved in alcohol-related marketing activities, started drinking alcohol, and $20 \%$ reported binge drinking [22], the study done among Axum University where about $608(80.4 \%)$ of the respondents were aware of problems or complications that could arise from alcohol [23], the study was done among Addis Ababa University, Medical students which are the prevalence of alcohol drinking in the last 12 months was 7\% [24]. Thus, the findings showed that the prevalence of alcohol drinking habit is more prevalent as compared to the study done in Pakistan, Mary land, USA report, and Addis Ababa University; however, it is less prevalent than the study done in US national survey and Axum University.

From this finds, the proportion of alcohol consumption by urban was lower as relative to the rural respondents since eighteen percent of respondents have used alcohol while thirty-six percent of rural respondents have used. This implies that rural respondents are two times consuming alcohol as compared to urban respondents. This study is consistently supported by the study done in [25] which is surprising that rural respondents $(1.8 \%)$ which large proportion of urban women alcohol users $(0.5 \%)$ thus seem quite disproportionate to the actual problem which is commonly observed in urban areas. The relatively low proportion maybe because the sampled urban area is a conservative middle-class locality.
Consumption of alcohol, conducted on Mizan Tepi University, estimate the prevalence of alcohol use as thirtyseven percent of males and sixteen percent of all females. The current study supported that the research done by Benegal V. [26] which estimated the prevalence of alcohol use as thirty percent of all adult males in the state and about one percent of all adult females. If one considers the fact that in many communities consumption of locally used alcohol is a tradition and a way of life, the reported abstention maybe for only alcohol that is purchased as well as community perception of genders. This finding is similar across the study done by Benegal V. [27].

From all sampled students, $54.2 \%$ of respondents have used alcohol at Mizan-Tepi University, in the case of College of Natural and Computational Science undergraduate students and which indicates that college students drink and that half of college student drinkers engage in heavy episodic drinking. Students who engage in excessive drinking impact, not just themselves rather than fellow students experience second-hand consequences ranging from disrupted study and sleep to physical and sexual assault. Furthermore, the institutions they attend expend valuable resources to deal with institutional and personal consequences of their behavior [28].

In this finds found that the difference in gender had a $\mathrm{p}<$ 0.05 ( $p$-value is 0.039 ) hence, meaning that gender deference does have any significant value with reference of alcohol abuse among the students and the age of the student did not have any significant association with the drinking of alcohol. Thus, the current study contradicts with the study done in alcohol Abuse among Egerton University Students in NjoroKenya [29].

Traditional drinks such as Araki, Teji, Tela and beer were commonly used by students those who came different residence. The aforementioned drinks, Teji, Tela and Areki are traditionally prepared and substitute the modern drink types like Wuski, Woine, Beer and extra were produced by factories at large. However, the student drinking habit increased on traditional drinks and the current study is comparatively consistent with WHO reports [30]. The association between frequency of drinking and ARH is presented in Table 3. Crude analysis (chi-square) showed strong significant and positive associations between more frequent drinkers of the sex of individuals [31].

\section{Conclusion}

The study used to assess the leading factors to alcoholism among undergraduate students in the College of Natural and Computational Science at Mizan Tepi University. The findings showed that the majority of college students have an alcohol drinking habit. This may indicate that there is an impact of students on the learning and teaching process at the University. It may have social, economic and political impacts at the country level. In the chi-square test, there is no significant association between alcohol drinking habits of undergraduate students with age, religion, place of the 
previous residence, income per month get from family, types of alcohol, father education level, and mother education level at the level of significance. Thus, it is concluded that there is an association to explore the leading factors to alcoholism among undergraduate students with sex individuals, departments and drinking initiation at a 5\% level of significance. In the binary logistic regression analysis, income per month get from family, types of drinking alcohol and initiation are the major influential factor that affects alcohol-drinking habit of undergraduates' students in the University.

\section{Recommendations}

Since the prevalence of alcohol-drinking habits of under graduate students is high, the management office should give more emphasis on the issue. Further analyses will be considered also covering large community of the institution to identify the problem in depth.

\section{List of Abbreviations}

ARH: Alcohol-Related Harm
MTU: Mizan-Tepi University
OR: Odd Ratio

\section{Ethics of Approval and Consent to Participate}

The study and the questionnaires were checked by department examiners as a committee before collecting the data. The survey data were collected from respondents from those who were volunteer to give information.

\section{Consent for Publication}

Not applicable since there is no protective individuals in the participants.

\section{Competing Interests}

The authors declare that they have no competing interests.

\section{Funding}

The author(s) disclosed receipt of the following financial support for the research, authorship, and/or publication of this article. The fund was sponsored by Mizan-Tepi University for data collection.

\section{Acknowledgements}

Our gratitude goes to Mizan-Tepi University for the permission of budget to do this study. In addition, we would like to thank data collectors who are supporting us by collecting basic information from respondents.

\section{References}

[1] G. M. Carter AC, Brandon KO, "The college and noncollege experience: a review of the factors that influence drinking behavior in young adulthood.," JStud Alcohol Drugs, vol. 5, no. 71, pp. 742-50, 2010.

[2] R. S. S. C. Byron L. Zamboanga, Janine V. Olthuis, Nicholas J. Horton, Elan C. McCollum, Jacqueline J. Lee, "Where's the House Party? Hazardous Drinking Behaviors and Related Risk Factors," NIH Public Access, vol. 23, no. 1, pp. 1-7, 2011.

[3] M. S. M. D., Clark, D. B., Beers, S. R., Soloff, P. H., Boring, A. M., Hall, J., Kersh, A. and Keshavan, "Hippocampus volume in adolescent- onset alcohol use disorders," Amer. J. Psychiat, no. 157, pp. 737-744, 2000.

[4] H. S. D. Dave, "Alchohol Demand and Risk Preference," $J$. Econ. Psychol., vol. 29, no. 6, pp. 810-831, 2008.

[5] Kaufman, S. F silver, P, and, "gender different in attitudes toward alcohol, tobacco and other drugs," Soc. Work, vol. 3, no. 42 , pp. 231-241., 1997.

[6] A. Kumar, K., Kumar, S., Singh, "'Prevalence and SocioDemographic Correlates of Alcohol Consumption: Survey Findings from Five States in India," Drug Alcohol Depend., no. 179, pp. 299-308, 2017.

[7] J. Jongenelis, M., Johnston, R., Stafford, “"Factors Associated with Parents" Belief in the Appropriateness of Providing Alcohol to their Child","' Subst. Use Misuse, vol. 53, no. 14, pp. 2281-2290, 2018.

[8] A. Lngle, H, and Turnham, "Attitudes knowledge and use of alcohol in university students," Couns. Psychol. Q., vol. 3, no. 9, pp. 309-323., 1996.

[9] O.. PARSONS, "Alcohol abuse and alcoholism. In: Nixon, S. J., ed. Neuropsychology for Clinical Practice. Washington, DC," Am. Psychol. Press, vol. 2, no. 27, pp. 175-201, 1996.

[10] J. Turrisi, R., Jaccard, J., Taki, R., Dunnam, H. and Grimes, "Examination of the short-term efficacy of a parent intervention to reduce college student drinking tendencies," Psychol. Addict. Behav, no. 15, pp. 366-372, 2001.

[11] S.. Tapert, S. F. and Brown, "Neuropsychological correlates of adolescent substance abuse," Four-year outcomes. J. Int. Neuropsychol. Soc, no. 5, pp. 481-493, 1999.

[12] F. Lane and M. Bethesda, "Trends in underage drinking in the united states," Off. Sci. Policy Commun. Natl. Inst. Alcohol Abus. Alcohol., pp. 20892-9304, 2013.

[13] C. H. J. Amer, "College binge drinking in the 1990s: A continuing problem," Results Harvard Sch. Public Heal. 1999 Coll. Alcohol Study, no. 48, pp. 199-210, 2000.

[14] W.. Cochran, "Sampling Techniques," Third Ed. John Wiley Sons Pte Ltd., Singapore, p. 428, 1977.

[15] M. S. Green, S. B., \& Thompson, "Structural equation modeling for conducting tests of differences in multiple means.," Psychosom. Med., no. 68, pp. 706-717, 2006.

[16] Agency CS, "Ethiopia Demographic and Health Survey," Addid Ababa, no. 515, 2016. 
[17] M. A. Mekuriya M, Grma T, Birhanu A, "Assessement of Substance Abuse and Associated Factors among Secoundary School Students in Ambo Town, Ehiopia.," J Addict Res Ther, vol. 10, p. 383, 2019.

[18] UNDOC, "World Drug Report," New york, United Nations Publ., 2014.

[19] S. M. E. al Kumesa ST, Mohammed MA, Gebremariam ET, Gelaw BK, "The Prevalence and Patterns of Social Drugs Abuse among Students of Rift Valey Univerity College, Bisheftu Campus, Bishoftu, Ethiopia," J PAharama Care Heal. Sys, vol. 2, p. 131, 2015.

[20] Niaz U, Siddiqui SS, Hassan S, Husain H, Ahmed S, "A survey of psychosocial correlates of drug abuse in young adults aged 16-21 in Karachi.," Pak JMed Sci., no. 21, pp. 271-277, 2005.

[21] Swendsen J, Burstein M, Case B, Conway KP, Dierker L, "Use and abuse of alcohol and illicit drugs in US adolescents: results of the National Comorbidity Survey-Adolescent Supplement.," Arch Gen Psychiatry, no. 69, pp. 390-398, 2012.

[22] Stoolmiller M, Wills TA, McClure AC, Tanski SE, Worth KA "Comparing media and family predictors of alcohol use: a cohort study of US adolescents.," BMJ Open, no. 2, p. $\mathrm{e} 000543,2012$.

[23] M. T. Measho G, Feleke A, "Psychoactive substances use and associated factors among Axum university students, Axum Town, North Ethiopia.," BMC Public Health, no. 13, p. 693, 2013.
[24] O. A. Oshodi OY, Aina OF, "Substance use among secondary school students in an urban setting in Nigeria: prevalence and associated factors.," African J Psychiatry, no. 13, pp. 32-57, 2010 .

[25] World Health Organization, "Burden and Socio-Economic Impact of Alcohol-The Bangalore study," Reg. Off. SouthEast Asia New Delhi, India., 2006.

[26] M. P. Benegal V, Gururaj G, "Report on a WHO Collaborative project on unrecorded consumption of Alcohol in Karnataka," India. (http//www.nimhans.kar.nic.in/deaddiction/Publications.html, accessed 16 June, 2006.

[27] Benegal V, "National experiences, India," alcohol public Heal. Addict., no. 100, pp. 1051-1056, 2005.

[28] H. Dave D, staffer, "alcohol demand and risk preference," $J$. Econ. Psychol., no. 29, pp. 810-831, 2008.

[29] A. O. Richard Kimuge Boitt, Monicah Lydia Boitt, Caleb Othieno, "Socio-Demographic Factors Associated with Alcohol Abuse among Egerton University Students in NjoroKenya," Coll. Heal. Sci. Sch. Med. Dep. Psychiatry, pp. 19676 -00202 .

[30] World Health Organization (WHO), "Global status report on alcohol," Geneva, 2004.

[31] D. S. A. D. Antai, G. B. Lopez, J. Antai, "Alcohol Drinking Patterns and Differences in Alcohol-Related Harm: A Population-Based Study of the United States," J. List Biomed Res Int v., p. 4095708, 2014. 